JARDEL DANTAS DA CUNHA

FREDERICO RIBEIRO DO CARMO

ORGANIZADORES

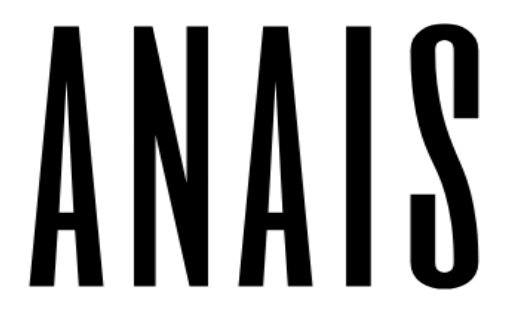

\title{
I SIMPÓSIO DE \\ DETRÓLEO E GÁS \\ DO ONSHORE \\ BRASILEIRO
}



ANAIS

I SIMPÓSIO DE PETRÓLEO E GÁS DO ONSHORE BRASILEIRO 


\section{Jardel Dantas Cunha}

Frederico Ribeiro do Carmo

organizadores

\section{ANAIS \\ I SIMPÓSIO DE PETRÓLEO E GÁS DO ONSHORE BRASILEIRO}

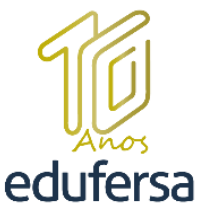

2021 


\section{(@) $(1) \Theta$}

O I SIMPÓSIO DE PETRÓLEO E GÁS DO ONSHORE BRASILEIRO foi editado pela EDUFERSA e está licenciado com uma Licença Creative Commons Atribuição-NãoComercial 4.0 Internacional, baseado no trabalho disponível em: https://edufersa.ufersa.edu.br. O conteúdo desta obra é de inteira responsabilidade dos autores.

\section{Reitora}

Ludimilla Carvalho Serafim de Oliveira

\section{Coordenador da EdUFERSA}

Mário Gaudêncio

\section{Projeto Gráfico}

EdUFERSA

\section{Revisão Ortográfica}

Natasha Yohanna Oliveira Mendes

\section{Conselho Editorial da EdUFERSA}

Mário Gaudêncio (Coordenador), Vanessa Christiane A. de S. Borba, Rafael Castelo Guedes Martins, Rafael Rodolfo de Melo, Fernanda Matias, Emanuel Kennedy Feitosa Lima, Rafael Lamera Giesta Cabral, Franselma Fernandes de Figueiredo, Antonio Diego Silva Farias, Luís Cesar de Aquino Lemos Filho e Pedro Fernandes de Oliveira Neto.

\section{Equipe Técnica da EdUFERSA}

Francisca Nataligeuza Maia de Fontes (Secretária), José Arimateia da Silva (Designer Gráfico) e Mário Gaudêncio (Bibliotecário).

Dados Internacionais de Catalogação na Publicação

S613 Simpósio de Petróleo e Gás do Onshore Brasileiro (1. : 2021 : Mossoró, Brasil).

I Simpósio de Petróleo e Gás do Onshore Brasileiro / organizado por Jardel Dantas Cunha e Frederico Ribeiro do Carmo. - Mossoró : EdUFERSA, 2021.

$50 \mathrm{f}$.

Anais do I Simpósio de Petróleo e Gás do Onshore Brasileiro, editado pela Editora da Universidade Federal Rural do Semi-Árido.

E-ISBN: 978-65-87108-13-1.

1. Petróleo. 2. Gás Natural. 3. Engenharia de Petróleo. I. Cunha, Jardel Dantas. II. Carmo, Frederico Ribeiro do. III. Título.

CDD: 665.5

Mário Gaudêncio (CRB-15/476)

Bibliotecário

Editora Associada 


\section{Jardel Dantas Cunha}

Frederico Ribeiro do Carmo

organizadores

\section{ANAIS \\ I SIMPÓSIO DE PETRÓLEO E GÁS DO ONSHORE BRASILEIRO}

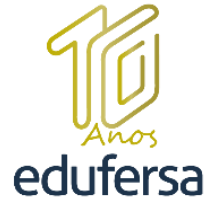

2021 


\section{Comissão Organizadora do Evento}

Jardel Dantas da Cunha (UFERSA)

Frederico Ribeiro do Carmo (UFERSA)

Marcos Allyson Felipe Rodrigues (UFRN)

\section{Comitê Científico do Evento}

Frederico Ribeiro do Carmo (UFERSA) - Presidente Antônio Robson Gurgel (UFERSA) - Vice-presidente Adriano Erique de Oliveira Lima (IFCE) Alcides de Oliveira Wanderley Neto (UFRN) Andréa Francisca Fernandes Barbosa (UFERSA) André Luís Novaes Mota (UFERSA) Antônio Rodolfo Paulino Pessoa (UFERSA) Edney Rafael Viana Pinheiro Galvão (UFRN) Fabricio Germano Alves (UFRN) Hosiberto Batista de Sant'Ana (UFC) Jardel Dantas da Cunha (UFERSA) Jennys Lourdes Meneses Barillas (UFRN) Julio Cezar de Oliveira Freitas (UFRN) Keila Regina Santana Fagundes (UFERSA) Luis Glauber Rodrigues (UFC) Luiz Felipe Monteiro Seixas (UFERSA) Marcos Allyson Felipe Rodrigues (UFRN) Patrícia Mendonça Pimentel (UFERSA) Rayanna Hozana Bezerril (UFRN) Regina Celia de Oliveira Brasil Delgado (UFERSA) Rodrigo César Santiago (UFERSA) Sibele Berenice Castellã Pergher (UFRN) 


\section{Sumário}

Introdução.

1 Identificação de fluidos e estimativa de produção por pistoneio - critérios de avaliação .... 13

2 Aplicação do planejamento experimental fatorial ampliado em estrela para estudo de adsorção usando ditomita e vermiculita 14

3 Estudos de Recuperação Avançada com Injeção de Polímeros em Reservatórios de Alta Permeabilidade da Bacia Potiguar 15

4 Aplicação de inibidor obtido da extração da espinheira santa (Maytenus ilicifolia Martius ex Reissek) para uso em fluidos de completação 16

5 Remoção de óleo diesel da água a partir do uso de tensoativos aniônicos. 17

6 Estudo comparativo da eficiência de cascas de banana e laranja na remoção de turbidez de fluido oleoso

7 Planejamento Operacional para Aquisição de Dados Sísmicos em Bacias Sedimentares Brasileiras 19

8 Levantamento e análise de dados de exploração e produção de petróleo e gás no cenário do Rio Grande do Norte 20

9 Proposta de percentuais globais de conteúdo local na exploração de petróleo onshore ..... 21

10 Recovery of lubricating oil-contaminated soils using bioremediation

11 Diagnosis of gravel deposits in oil production area in the West Potiguar Region: soil fertility

12 Bioremediation for recovery of used lubricating oil-contaminated soils.

13 Dignosis of gravel deposits in oil production area in the West Potiguar Region: soil physics

14 Utilização de um software de otimização comercial para análise de incertezas e ajuste histórico das propriedades de um reservatório de petróleo com características onshore e comparação com o método de ajuste manual

15 Requisitos metrológicos legais para medição fiscal aplicados a unidades flutuantes de produção, armazenamento e transferência de petróleo (FSPO)

16 Ajuste de dados de histórico obtidos a partir de análise de incertezas, aplicadas ao campo sintético de Tubarão Branco, com utilização de simulador comercial 
16 zapGERISK

17 Acoplamento iterativo explícito fluxo-geomecânica de reservatório trifásico com black-oil

18 Inteligência artificial versus método assistido: diferenças e oportunidades na análise de incertezas e ajuste de histórico em reservatório onshore com injeção de $\mathrm{CO}_{2}$

19 Comparação de métodos de recuperação por injeção de $\mathrm{CO}_{2}$ ou água sob diferentes perspectivas de refino de grid em reservatório de características do onshore brasileiro

20 Avaliação de correlações empíricas para o cálculo do fator de compressibilidade de gás natural de campos brasileiros 33

21 Estudo da solubilidade e caracterização de solvente aplicado como líquido dessecante para absorção da água presente no gás natural 34

22 Efeito da temperatura na cimentação de poços petrolíferos 35

23 Otimização do fator de recuperação de óleo para um campo maduro aliado ao armazenamento de dióxido de carbono 36

24 Realização de análise PVT em amostra sintética de derivados de petróleo 37

25 Xisto Betuminoso: uma Alternativa Energética 38

26 Caracterização de argila atapulgita aplicada a fluidos de perfuração não aquosos 39

27 Coletores solares para preaquecimento de água em Reservatórios de óleo Pesado 40 28 Avaliação de correlações de translação de volumes acopladas à equação cúbica de Peng e Robinson para predição do volume molar de hidrocarbonetos

29 Tratamento de águas produzidas de exploração petrolífera contaminadas com sulfetos .. 42 30 Revestimento de polietileno de alta densidade (PEAD) como sistema de proteção contra corrosão em oleodutos no RN

31 Análise de integridade por elementos finitos de compósito polimérico tripla camada aplicado em tubulações de petróleo

32 Análise de viabilidade econômica da injeção de $\mathrm{CO}_{2}$ em reservatórios maduros

33 Análise de molhabilidade em rocha calcária do RN com adsorção de tensoativo aniônico 46 34 Aplicação de resina em poços de petróleo

35 Predição da velocidade do som de hidrocarbonetos nas fases líquida e vapor utilizando as equações cúbicas de Soave-Redlich-Kwong e Peng-Robinson

36 Otimização na perfuração de poço onshore de alta instabilidade no Recôncavo Baiano utilizando-se nanotecnologia e motor direcional de alta performance...... 



\section{Introdução}

Localizado no Nordeste do Brasil, o estado do Rio Grande do Norte possui 93\% do seu território nos limites do Semiárido brasileiro, além de uma rica base de recursos naturais como sal, petróleo, gás natural e calcário. Segundo o Anuário Estatístico da Agência Nacional do Petróleo, Gás Natural e Biocombustíveis (ANP) de 2020, o estado do Rio Grande do Norte foi o maior produtor de petróleo e o sexto de gás natural em campos terrestres (onshore) do Brasil no ano de 2019.

A Bacia Potiguar localiza-se na porção mais oriental do Nordeste brasileiro, estendendo-se pelos estados do Rio Grande do Norte e do Ceará. A exploração de hidrocarbonetos na bacia iniciou-se em 1949, com mapeamentos de superfície e levantamentos gravimétricos e magnetométricos conduzidos pelo Conselho Nacional do Petróleo (CNP). Após a criação da Petrobras, em 1956, a estatal iniciou estudos exploratórios na região.

A partir dos referidos levantamentos, descobriram-se os campos de Ubarana (1973), Agulha (1975), na plataforma continental, e do Campo de Mossoró (1979), na porção terrestre. Destaca-se que a estatal, com o objetivo de melhorar a produção de hidrocarbonetos no país, ampliou a produção de óleo e gás na Bacia Potiguar, em virtude da descoberta de outros importantes campos: Fazenda Belém (1980), Alto do Rodrigues (1981), Estreito, Fazenda Pocinho, Guamaré, Serraria (1982), Lorena, Upanema (1984), Canto do Amaro (1985), entre outros.

A produção dos campos onshore brasileiros é demasiadamente insignificante em relação aos campos offshore. Essa diferença ficou ainda mais discrepante após o início da produção dos campos do pré-sal, em 2010. A partir disso, com o intuito de concentrar seus recursos em seus campos de maior produtividade, a Petrobras iniciou a venda de muitos de seus campos onshore.

Em resposta à queda dos investimentos no segmento onshore, o Ministério de Minas e Energia, em 2017, anunciou o Programa de Revitalização da Atividade de Exploração e Produção de Petróleo e Gás Natural em Áreas Terrestres (REATE), cujo objetivo é a revitalização das atividades de Exploração e Produção (E\&P) em áreas terrestres no território nacional, estimulando o desenvolvimento local e regional e aumentando a competitividade da indústria petrolífera onshore do país.

As ações mencionadas são benéficas para todos os envolvidos, uma vez que os menores produtores, obtendo mais oferta de campos, tendem a ampliar a produção dos campos marginais. No outro extremo, a Petrobras beneficia-se ao alocar mais de seus recursos em seu plano de negócios e na extração de petróleo em campos offshore. Por fim, ampliando a produção onshore, aumenta-se a arrecadação a partir de royalties, o que tende a ser benéfico para a população local, elevando os níveis dos indicadores sociais e possibilitando um maior esforço financeiro na proteção do meio ambiente local. 
A partir do atual cenário, a Universidade Federal Rural do Semi-Árido (UFERSA) - em parceria com a Redepetro e o Sebrae - tem o prazer de apresentar o I SIMPÓSIO DE PETRÓLEO E GÁS DO ONSHORE BRASILEIRO, cujo objetivo é reunir profissionais, estudantes e pesquisadores da área de petróleo e gás com ênfase em exploração onshore. 


\title{
1 Identificação de fluidos e estimativa de produção por pistoneio $-\bar{m}$ critérios de avaliação
}

\author{
Bruno Leonardo Santos de Cerqueira \\ Gleidiane Silva Santos Cordeiro
}

O presente trabalho descreve os equipamentos utilizados, procedimento da atividade e critérios de encerramento do pistoneio mecânico para elevação de fluidos em poços de petróleo utilizando sonda de produção terrestre, processo cujo objetivo é identificar os fluidos produzidos e estimar a produtividade do poço durante a fase de completação. Foram abordados superficialmente os métodos alternativos de pistoneio através de equipamentos dedicados para esse fim: a unidade móvel de pistoneio e o Recoil ${ }^{\mathrm{TM}}$. A pesquisa não só descreve o pistoneio de forma geral, mas também propõe um critério para finalização do procedimento, garantindo resultados confiáveis, redução no tempo de intervenção da sonda no poço e, consequentemente, redução dos custos. Grande parte dessa pesquisa foi embasada em entrevistas realizadas com os profissionais da área de petróleo, mais especificamente profissionais que atuam ou já atuaram executando o pistoneio. Também foram utilizados relatórios relativos à atividade de pistoneio durante intervenções em poços do campo da Fazenda Bálsamo (Esplanada-BA). Foram selecionados nove relatórios e gerados gráficos que facilitam a interpretação do comportamento do poço durante o pistoneio, criando um critério de parada através das variáveis, nível de fluido final e TAL (Teor de Água Livre). Essa representação gráfica pode ser interpretada por qualquer pessoa sem grande conhecimento específico em pistoneio.

Palavras-chave: Avaliação. Critério. Fluido. Pistoneio. Produção. 


\title{
2 Aplicação do planejamento experimental fatorial ampliado estrela para estudo de adsorção usando ditomita e vermiculita
}

\author{
Antonio Kennedy da Silveira Brito \\ André Luís Novais Mota
}

A indústria petrolífera há muito tempo enfrenta problemas ambientais. A água produzida é um desses desafios, haja vista seu enorme potencial poluidor. Normas ambientais foram criadas com o objetivo de minimizar esses possíveis danos. No Brasil existe a Resolução CONAMA $n^{\circ}$ 393/07, que regula esse tipo de empreendimento, sendo seu principal parâmetro o teor de óleos e graxas - TOG. Diante disso, estudos foram realizados visando encontrar novas formas de tratamento que sejam eficientes e financeiramente viáveis. Um método muito estudado é a adsorção, que usa diversos tipos de adsorvente e em especial as argilas. Nesse trabalho foi proposto executar um estudo de adsorção comparativo usando os argilominerais diatomita e vermiculita como adsorventes, em banho finito, e ainda aplicou-se um planejamento experimental para analisar duas variáveis do processo (o pH e a razão entre massa de adsorvente e o volume da solução) e obter as melhores condições para remoção do corante, o planejamento usado foi o fatorial ampliado rotacional (tipo estrela). Para facilitar o controle das características do efluente a ser tratado, foi usado um corante já conhecido e muito estudado: o corante reativo azul BF-5G, pois controlar as variáveis de um efluente sintético de petróleo ou derivados é bastante complexo, principalmente devido à formação de emulsão em sua preparação, além de que o aparelho usado para analisar tanto o efluente quanto o produto tratado foi o espectrofotômetro, que provavelmente apresentaria problemas ao analisar um efluente de petróleo. Para os dois adsorventes, foi observado que o $\mathrm{pH}$ da solução é a variável que mais influencia no processo, e seu aumento proporciona melhores resultados de remoção. O estudo mostrou que tanto a diatomita quanto a vermiculita podem ser considerados bons materiais adsorventes, atingindo porcentagens de remoção superiores a $80 \%$, e a diatomita se mostrou ainda mais eficiente na remoção dos contaminantes que a vermiculita.

Palavras-chave: Água Produzida. Petróleo. Adsorção. Vermiculita. Diatomita. 


\section{Estudos de Recuperação Avançada com Injeção de Polímeros em Reservatórios de Alta Permeabilidade da Bacia Potiguar}

Beatriz Ferraz Martins

Antonio Robson Gurgel

Esse trabalho consiste em estudos de simulação numérica de reservatórios utilizando um modelo numérico homogêneo e semissintético com características de um campo de óleo da Bacia Potiguar. O objetivo é analisar melhorias no fator de recuperação (FR) através da injeção do polímero poliacrilamida parcialmente hidrolisada. Para a realização deste estudo, foi utilizado o simulador numérico de reservatórios tNavigator da empresa Rock Flow Dynamics. O modelo do óleo tem um ${ }^{\circ} \mathrm{API}$ em torno de 24,3 e o reservatório projetado possui dimensões de $284 \mathrm{~m} \times 284 \mathrm{~m} \times 6 \mathrm{~m}$, possuindo permeabilidade média de $2400 \mathrm{mD}$ com esquema de injeção do tipo five-spot invertido com projeto de vinte anos de simulação. A metodologia adotada consistiu em injetar água com vazão de injeção 0,1 volume poroso por ano, com concentrações de 500, 1000 e 2000 ppm. Para isso, as seguintes estratégias de injeção foram utilizadas: Injetar água do início ao fim do projeto, injetar polímero com água do início ao fim do projeto, injetar água a partir do $5^{\circ}$ ano até o final do projeto e injetar polímero a partir de um corte de água de $80 \%$ para os todos os casos onde se injetou água. De forma geral, em todos os esquemas de injeção apresentados o aumento da concentração de polímero na injeção resulta em um aumento no FR de óleo e a diminuição da produção de água para o tempo de simulação de 20 anos. O melhor resultado apresentado foi com concentração de 2000 ppm com injeção de polímeros após o corte de água de 80\%, para o caso onde se injetou água a partir do quinto ano. Para essa simulação, houve um acréscimo de 5,78\% no FR. Da mesma forma, destaca-se que a injeção de polímero desde o início diminuiu a produção de água em 9,06\% para a concentração de 2000 ppm quando comparado ao caso onde se injetou água a partir do quinto ano.

Palavras-chave: Simulação numérica. Injeção de polímeros. Fator de recuperação. 


\section{Aplicação de inibidor obtido da extração da espinheira santa (Maytenus ilicifolia Martius ex Reissek) para uso em fluidos de completação}

Jardel Hugo Gonçalves Paiva Jardel Dantas da Cunha

Andrea Francisca Fernandes Barbosa

Victor Augusto Freire Costa

Gecilio Pereira da Silva

O fluido de completação é, por definição, uma solução isenta de sólidos, podendo ser salina, emulsões invertidas e petróleo com baixo teor de sólidos. Nesse sentido, os fluidos de completação mais usados na indústria do petróleo são os caracterizados como soluções salinas, especialmente o $\mathrm{NaCl}$. Entretanto existe um grande problema em utilizar esse tipo de solução, pois estas podem provocam corrosão na coluna, revestimento e outros equipamentos, devido ao alto teor de sal presente que influencia no processo. Esta corrosão pode ser reduzida com o uso de um inibidor adequado, ainda que possua baixa viscosidade, o que dificulta o controle do filtrado. Os inibidores de corrosão são substâncias que, quando adicionadas em pequenas quantidades, diminuem gradualmente o processo corrosivo. Dessa forma, a segurança e os problemas ambientais causados pelos inibidores de corrosão comerciais usados na indústria têm sido questionados. Nessa vertente surgem diversas pesquisas com compostos orgânicos naturais atuando como inibidores, devido a algumas vantagens: serem considerados de baixo custo, não tóxicos e principalmente serem aceitáveis do ponto de vista ecológico. O objetivo do presente trabalho consiste em avaliar a utilização da Espinheira Santa como um potencial inibidor de corrosão da linha verde. Foram confeccionados fluidos de completação à base de cloreto de sódio, nas concentrações 50, 100 e 150 lb/Gal., sendo variado o parâmetro de dosagem de inibidor orgânico, sendo essas concentrações de 1\%, 2\% e 3\% de extrato da espinheira santa. Os resultados obtidos para as concentrações com $1 \%$ de inibidor tiveram eficiência em torno de $80,85 \%$ para $50 \mathrm{lb} / \mathrm{gal}, 69,74 \%$ para $100 \mathrm{lb} / \mathrm{gal}$ e 65,00\% com $150 \mathrm{lb} / \mathrm{gal}$. Os inibidores com concentrações acima de $2 \%$ e $3 \%$ apresentaram nos fluidos de completação estudados eficiências superiores a $90 \%$ para todos os casos.

Palavras-chave: Inibidor. Corrosão. Espinheira santa. Extrato. 


\title{
5 Remoção de óleo diesel da água a partir do uso de tensoativos aniônicos
}

\author{
Edja Tainara de Souza Querino \\ Vivian de Araujo Candeia Dutra \\ Paloma Joyce do Nascimento \\ Manoel Reginaldo Fernandes
}

A poluição é um dos grandes problemas ambientais atualmente, acarretado pelo crescimento populacional desenfreado junto com as novas tecnologias, desencadeando impactos ambientais. Entre os impactos está o petróleo, que unido aos seus derivados na presença de água desempenha efeitos múltiplos na natureza devido à sua baixa degradabilidade. Os prejuízos causados ao meio ambiente são devidos à omissão e falta de fiscalização necessária para que o dano não ocorra. Nesse contexto, o objetivo deste trabalho é promover a remoção de óleo diesel da água baseado no uso de tensoativos, obtidos a partir do óleo de girassol com água produzida e, posteriormente, cálcio. A presença de tensoativo e cálcio no meio formam um precipitado, que, quando agitado, se une formando flocos. A presença dos flocos estabelece uma superfície adsorvente, atraindo a água produzida e removendo-a completamente após um processo de filtração. O parâmetro analisado nesse estudo foi a turbidez, que é originada pela suspensão de materiais sólidos em seu meio. Dessa forma, as amostras foram analisadas em turbidímetros, onde foi possível constatar ao fim do estudo que a água está dentro dos padrões de qualidade, podendo ser utilizada em processos de irrigação.

Palavras-chave: Tensoativos. Óleo diesel. Floculante. Turbidímetro. 
6 Estudo comparativo da eficiência de cascas de banana e laranja na remoção de turbidez de fluido oleoso

\author{
Cinthia Silva Almeida \\ Matheus Vinícius Costa Pereira \\ Pamella Domingos Paulino \\ Regina Celia de Oliveira Brasil Delgado \\ Rodrigo Cesar Santiago
}

O objetivo deste trabalho é analisar e comparar a eficiência de cascas de banana e laranja como adsorventes na remoção de turbidez de fluido sintético oleoso, com o propósito de aplicar esses resíduos no tratamento de água produzida em poços de petróleo. Essa água apresenta uma composição complexa e elevada quantidade de contaminantes tóxicos, necessitando ser tratada. A técnica de adsorção vem sendo aplicada nesse tipo de tratamento. A busca por adsorventes mais baratos e acessíveis vem crescendo atualmente e, dessa forma, o uso de resíduos naturais torna-se uma alternativa interessante. No Brasil, o alto consumo de laranja e banana gera um grande acúmulo de cascas, e a disposição destas necessita de solução ambientalmente eficiente. As cascas utilizadas no trabalho foram obtidas no Restaurante da Universidade Federal Rural do Semi-Árido, que fornece as frutas semanalmente em seu cardápio. O material foi triturado, lavado e seco, e posteriormente submetido à classificação granulométrica, para ser testado na mesma faixa de granulometria (-28+35 mesh). A composição química das cascas foi obtida através de fluorescência de raios $X$ por energia dispersiva (EDX). Foi preparado um fluido contendo 20\% de óleo diesel S500 em água destilada. Os ensaios de adsorção foram realizados em banho finito utilizando 3 e 5 gramas dos adsorventes em contato com quantidade fixa do fluído $(200 \mathrm{~mL})$, e, em seguida, as amostras foram analisadas pela técnica da turbidez. Os resultados obtidos da análise química mostraram que as cascas de laranja e banana são constituídas principalmente de óxido de cálcio, possuindo respectivamente $73,1 \%$ e $62,5 \%$ em concentração. A turbidez inicial do fluido oleoso foi de 723 NTU, e após os ensaios em banho finito foi verificado que houve uma diminuição superior a 85\% usando cascas da laranja e de $97 \%$ usando cascas de banana. Logo, o trabalho colabora para a resolução de problemas relacionados tanto à água produzida quanto ao destino de resíduos agroindustriais.

Palavras-chave: Banana. Laranja. Fluido oleoso. 


\section{Planejamento Operacional para Aquisição de Dados Sísmicos em Bacias Sedimentares Brasileiras}

Tiago Alerrandro Paulino Arrais Regina Celia de Oliveira Brasil Delgado Jardel Dantas da Cunha Antonio Robson Gurgel

$O$ advento da sociedade moderna traz consigo uma demanda cada vez maior por energia, que é a força motriz por trás de grande parte dos mais diversos segmentos das indústrias. O petróleo é uma das principais fontes de energia que contribuiu intensamente para o desenvolvimento da humanidade, sua exploração remonta a tempos antigos onde ainda se dependia do acaso para encontrá-lo. A crescente demanda por petróleo torna cada vez maior a necessidade de se ter precisão quanto à localização de uma acumulação de hidrocarbonetos, tendo em vista os altos custos e riscos da perfuração de um poço. Pesquisas no campo da prospecção de petróleo vêm sendo desenvolvidas no mundo inteiro de modo que atualmente os métodos sísmicos empregados são bastante precisos na localização de novas jazidas. Algo tão importante quanto à prospecção em si, é o planejamento operacional que precede e embasa a campanha de prospecção. A presente pesquisa teve como objetivo analisar de forma qualitativa os relatórios elaborados por duas empresas do segmento de prospecção sísmica por reflexão, sobre o planejamento operacional para aquisição de dados em bacias sedimentares brasileiras, a fim de gerar conhecimento dessa importante área da indústria petrolífera. Para atender à solicitação, as empresas que colaboraram com esse estudo terão seus nomes preservados. O estudo consistiu em compreender e analisar todas as etapas do planejamento operacional de campanhas sísmicas. Da análise realizada nos relatórios foi observado que existe uma forte correlação entre os aspectos considerados pelas empresas, estando estes relacionados a três vertentes principais: custos, segurança e aspectos legais. Logo, a fase de planejamento operacional para aquisição de dados sísmicos é de fundamental importância para o sucesso da operação, bem como para proteção ambiental das áreas onde as operações ocorrem, segurança das equipes envolvidas e controle de despesas.

Palavras-chave: Prospecção sísmica. Petróleo. Planejamento. 


\title{
8 Levantamento e análise de dados de exploração e produção de petróleo e gás no cenário do Rio Grande do Norte
}

\author{
Yedna Maria de Oliveira Silva \\ André Luís Novais Mota \\ Kalyanne Keyly Pereira Gomes \\ Regina Celia de Oliveira Brasil Delgado \\ Rafaella Sales Mendonça Alheiros
}

A importância do petróleo no mundo atual deve-se por ser um recurso natural que possui uma composição química favorável, de modo que, através de seu fracionamento, são produzidos derivados de grande valor energético, além de não energéticos e insumos para a indústria petroquímica. A dependência destes derivados representa um forte impacto na economia, meio ambiente e bem-estar da sociedade. Desse modo, informações a respeito da exploração e produção de petróleo e gás são imprescindíveis para o setor industrial e para o setor acadêmico, uma vez que as referências bibliográficas carecem de dados mais atuais, pois trata-se de um assunto em constante atualização. O presente trabalho teve como objetivo fazer um levantamento dos dados de exploração e produção de petróleo e gás no cenário do Rio Grande do Norte, contextualizando, de forma cronológica, o balanço do setor do petróleo aos seus respectivos fatores de impacto. Para isso, foram utilizados os dados relativos à exploração e produção de petróleo e gás do RN e do Brasil, bem como de seus derivados que são disponibilizados pela Agência Nacional do Petróleo, Gás e Biocombustíveis (ANP). Esses dados foram trabalhados, analisados e contextualizados com fatores impactantes ocorridos em torno do setor do petróleo no período em análise, e comparados com a tendência de produção nacional. A partir desses dados obtidos e das discussões pertinentes, pode-se notar uma tendência de redução na produção de petróleo no RN nos últimos anos, podendo ser justificado pelo amadurecimento de alguns campos de produção, evidenciado pelo aumento na razão água-óleo produzida. Outro fator de impacto está ligado a uma redução no investimento do setor, identificada pela redução de poços perfurados no estado, além de outros aspectos políticos e econômicos. Em contrapartida, observou-se um aumento na produção nacional, acarretado pela descoberta de novas reservas, investimentos no setor, avanços tecnológicos, fatores geopolíticos, dentre outros.

Palavras-chave: Petróleo. Gás. Produção. Exploração. 


\title{
9 Proposta de percentuais globais de conteúdo local na exploração de petróleo onshore
}

\author{
Guilherme Marinho de Araújo Mendes \\ Fabrício Germano Alves
}

O objetivo do presente trabalho é apresentar argumentos favoráveis e desfavoráveis à fixação de percentuais globais de conteúdo local, com foco onshore, em face do modelo anterior de fixação global acrescido de itens e subitens. A explanação possui abordagem qualitativa, de método hipotético-dedutivo, a partir da evolução regulatória da Política de Conteúdo Local no setor do petróleo. A implementação da Política de Conteúdo Local pela ANP tem a finalidade de estimular o desenvolvimento da indústria brasileira, assegurando a preferência de fornecedores nacionais no suprimento de bens e serviços da atividade de exploração de petróleo. Na realização da 7ạ Rodada da ANP (2005) foi fixado que os percentuais deveriam ser globais acrescidos de itens e subitens, com alocação de pesos de conteúdo local em cada item. A principal crítica quanto ao critério global definido a partir de itens e subitens aduz que esse modelo não é simples, claro e prático como determina o art. 40 da Lei 9.478/97, o qual exige critérios objetivos. A complexidade do preenchimento de planilhas, medição, engessamento, além das variáveis cabíveis como o preço internacional do petróleo, não torna tarefa fácil conseguir cumprir os percentuais estipulados. Em 2017, a Resolução CNPE no 07 definiu um novo modelo simplificado: para blocos onshore, são exigidos apenas percentuais globais de $50 \%$ (seja fase de exploração ou desenvolvimento). 0 argumento contrário à fixação de percentual apenas global é no sentido de que as empresas petroleiras irão apenas contratar no país serviços de menor complexidade tecnológica e que a ausência de fixação de itens e subitens acarretará redução brusca de atividade, desemprego, atrofia de empregos qualificados e tecnologia; um desmonte da política. Conclui-se que a implementação de uma reserva de mercado excessivamente rígida e burocrática não culminou em eficiência industrial, sendo a simplificação regulatória global mais condizente com a complexidade do setor.

Palavras-chave: Petróleo. Conteúdo local. ANP. 


\section{Recovery of lubricating oil-contaminated soils using bioremediation}

Ana Quézia Carvalho Braga

Celsemy Eleutério Maia

José Mariano da Silva Neto

Dayanne Támela Soares Nogueira

Elton Dannilo Carvalho Braga

Bioremediation is a biological technique that stimulates soil microbiota to recover degraded areas by organic compounds, especially those produced by the petroleum industry. The aim of this work was to evaluate the recovery of lubricating oil-contaminated soil using bioremediation. Two type of soils were used, Vertisols and Ultisols, which were contaminated with five concentrations of unused lubricating oil $(0 \%, 1 \%, 3 \%, 5 \%$ and $10 \% \mathrm{w} / \mathrm{w})$ with three replications in a randomized block design, and each portion having $100 \mathrm{~g}$ of soil. Lubricating oil degradation was evaluated weekly indirectly by respirometry, where the treatments were placed in closed vessels with $\mathrm{NaOH}$ to capture the $\mathrm{CO} 2$ produced in the decomposition of the lubricating oil and quantified by titration. The experiment was conducted for 56 days, when it was found that the recovery of both soils was similar with average C-CO2 production of 936 and $969 \mathrm{mg} \mathrm{kg}-1$ for Vertisols and Ultisols, respectively, with oil decomposition rate for both soils of approximately $15 \mathrm{mg}$ kg-1day-1.

Keywords: Recovery of degraded areas. Petroleum. Oil spill. 


\title{
11 Diagnosis of gravel deposits in oil production area in the West Potiguar Region: soil fertility
}

\author{
Ana Quézia Carvalho Braga \\ Celsemy Eleutério Maia \\ José Mariano Silva Neto \\ Dayanne Támela Soares Nogueira \\ Elton Dannilo Carvalho Braga
}

Gravel is an aggregate of natural origin with varying particle size and formed by fragments of rocks and minerals, it is used in the oil chain, at the base of onshore oil wells, and in the construction of access roads to these wells. This material is taken from deposits that must be recovered after exploration. It is necessary to evaluate the fertility of these areas, mainly related to phosphorus, $\mathrm{pH}$ and organic matter, aiming at the removal of factors that negatively affect the revegetation of the recovering area. The aim of this work was to make a soil fertility diagnosis in eight gravel deposits located in the West Potiguar petroleum production areas. For this, the deposits substrate was sampled, collecting 20 points in each area at a depth of $20 \mathrm{~cm}$, and this material was mixed to make a composite sample. $\mathrm{pH}$, carbon (C), phosphorus (P), calcium (Ca), magnesium (Mg), potassium (K), sodium ( $\mathrm{Na})$, aluminum (Al) and potential acidity $(\mathrm{H}+\mathrm{Al})$ were determined and sum of bases (SB), cationexchange capacity (CEC) and base saturation (BS) were calculated. From the evaluated areas only one showed low values for $\mathrm{Ca}, \mathrm{Mg}, \mathrm{K}, \mathrm{CEC}$ and $\mathrm{BS}$. For $\mathrm{pH}, 25 \%$ presented low values and all areas presented very low carbon and phosphorus values, while all deposits presented aluminum. Therefore, it can be concluded that some deposits need liming to increase $\mathrm{pH}, \mathrm{Ca}$ + Mg and neutralize Al and that phosphate fertilization should be applied to organic matter, mainly to increase CEC and water retention for the areas revegetation.

Keywords: Revegetation. Recovery of degraded areas. Soil analysis 


\section{Bioremediation for recovery of used lubricating oil-contaminated}

soils

José Mariano da Silva Neto

Ana Quézia Carvalho Braga

Celsemy Eleutério Maia

Dayanne Támela Soares Nogueira

Elton Dannilo Carvalho Braga

Disposal of motor vehicle lubricating oil should be done in such a way as to avoid soil contamination, especially due to its high toxicity to the environment, however accidents can occur and the bioremediation technique can be used to decontaminate the area. The aim of this work was to use the bioremediation technique to recover soil contaminated by used automotive lubricating oil. Two type of soils were used, Vertisols and Ultisols, which were contaminated with five concentrations of used lubricating oil $(0 \%, 1 \%, 3 \%, 5 \%$ and $10 \% \mathrm{w} / \mathrm{w})$ with three replications in a randomized block design, and each portion having $100 \mathrm{~g}$ of soil. Lubricating oil degradation was indirectly evaluated by respirometry, where the treatments were placed in closed vessels with $\mathrm{NaOH}$ to capture the $\mathrm{CO} 2$ produced in the decomposition of the lubricating oil. C-CO2 production increased linearly with increasing oil concentration in Vertisols, with a C-CO2 production rate of $79.7 \mathrm{mg} \%-1$ of oil. For Ultisols, C-CO2 production peaked at a concentration of approximately $18 \%$, reducing degradation after this concentration. The different behavior between these two soils is probably due to the higher fertility of Vertisols, contributing to a greater soil microbiota biostimulation, thus increasing bioremediation, consequently the soil recovery.

Keywords: Recovery of degraded areas. Petroleum. Oil spill. 


\title{
13 Dignosis of gravel deposits in oil production area in the West Potiguar Region: soil physics
}

\author{
Elton Dannilo Carvalho Braga \\ Celsemy Eleutério Maia \\ José Mariano da Silva Neto \\ Ana Quézia Carvalho Braga \\ Dayanne Támela Soares Nogueira
}

By law every degraded area has to be recovered, as it is the case with gravel deposits, whose material is used in the oil production chain. In the recovery areas process it is recommended to remove the limiting factors to plant growth, removing first the physical factors, then the chemical and finally the biological, aiming to optimize the area revegetation. The objective of this work was to make a soil physics diagnosis in eight gravel deposits located in the West Potiguar petroleum production areas. For this, sampling was performed from the substrate in the region of the deposits, collecting 20 points in each area at a depth of $20 \mathrm{~cm}$, and this material was mixed to make a composite sample. Bulk (BD) and particle (PD) density, sand, silt and clay contents, field capacity (FC), permanent wilting point (PWP) were determined and total porosity (TP) and available water (AW) were calculated. Regarding the evaluated areas texture, five presented sandy clay loam and three sandy clay. All bulk densities were greater than $1.25 \mathrm{~kg} \mathrm{dm}-3$ and particle density ranged from 1.89 to $2.63 \mathrm{~kg} \mathrm{dm}-3$, with total porosity ranging from $26.37 \%$ to $49.43 \%$. Concerning water retention, FC ranged from $18.45 \%$ to $33.55 \%$ and PWP from $7.34 \%$ to $21.61 \%$, with AW ranging from $10.85 \%$ to $17.81 \%$. With this, it can conclude that the substrates have texture to a sandy tendency, causing a lower water retention, which could be solved with the application of organic matter to increase the water retention capacity, as well as the soil porosity, increasing the success in the revegetation of these areas.

Keywords: Revegetation. Recovery of degraded areas. Water retention. 


\section{Utilização de um software de otimização comercial para análise de incertezas e ajuste histórico das propriedades de um reservatório de petróleo com características onshore e comparação com o método de ajuste manual}

Emanuelle Fernandes Braga Francisco Helson de Lima Neres Tiago Mendes Tavares

Yuri Nunes Saraiva Luis Glauber Rodrigues

O caso em estudo é um reservatório de óleo maduro, característico das condições onshore, apresentando recuperação avançada de óleo a partir da injeção de água. O modelo leva em consideração as heterogeneidades referentes à porosidade e às permeabilidades, sendo composto por 4 poços produtores e 1 injetor, em five-spot invertido. O objetivo do trabalho é comparar dois métodos para o ajuste das propriedades do modelo, visando à obtenção de resultados mais próximos da realidade do reservatório, sem refinamento da malha de simulação. No primeiro método, foi realizado o refinamento de grid para obtenção dos parâmetros de propriedades mais próximas do real. Em seguida, foi realizado o ajuste manual dos parâmetros: volumes acumulados de óleo e água, pressão média do reservatório e fator de recuperação. Esse ajuste foi feito por meio da alteração dos pontos de máximo e mínimo das curvas de permeabilidade relativa. No segundo método foi utilizado o software CMOST AI - CMG ${ }^{\circledR} 2019.1$ para a realização da análise de sensibilidade dos parâmetros em estudo; em seguida, foi realizado o ajuste histórico em relação ao caso mais refinado. Como resultado, o método manual não atingiu plenamente o ajuste em todas propriedades, no entanto, o software comercial atingiu esse objetivo. Portanto, concluiu-se que os valores calculados pelo simulador, no ajuste histórico, poderão servir como dados de entrada, no caso não refinado, e dessa forma obter os valores para as curvas de produção acumulada de óleo e água equivalentes ao caso refinado. Assim, as simulações acontecerão em um tempo menor e ainda serão obtidos valores representativos do reservatório.

Palavras-chave: Ajuste histórico. Análise de incertezas. Mudança de escala. Modelagem e simulação. 


\title{
15 Requisitos metrológicos legais para medição fiscal aplicados unidades flutuantes de produção, armazenamento e transferência de petróleo (FSPO)
}

\author{
Hélio Damásio de Lima Filho \\ Andrea Francisca Fernandes Barbosa \\ Jardel Dantas da Cunha
}

A produção de petróleo e gás natural no Brasil é de grande importância, pois, como é por lei um commodity nacional, o volume produzido deste bem influencia diretamente a receita da união, estados e municípios, graças a uma série de leis nacionais que promovem a divisão dos recursos oriundos da sua exploração. Diante dos grandes volumes de produção atual, especialmente em alto mar nas plataformas de exploração do tipo FPSO, é necessário um controle metrológico rígido. A Agência Regulamentadora de Petróleo e Gás Natural do Brasil (ANP) é quem tem a função de garantir a correta medição deste produto, a medição realizada com esta finalidade é denominada medição fiscal. Para padronizar e regulamentar as medições volumétricas de óleo, a ANP publicou um documento que rege os requisitos metrológicos dos sistemas de medição, esse documento é denominado Regulamento Técnico de Medição de Petróleo e Gás Natural (RTM). A seleção dos equipamentos que irão compor o sistema de medição, a forma como este deve ser projetado e inserido na planta de processo e os mecanismos de apoio preconizados pelo RTM devem atender aos requisitos metrológicos legais e a uma série de normas nacionais e internacionais. Um estudo detalhado de documentos metrológicos normativos e legais que regem a medição fiscal no Brasil será realizado a fim de agrupar as exigências de projeto e seleção dos equipamentos de um sistema de medição de volume de óleo. O objetivo deste trabalho é, a partir desses requisitos, definir normas de abrangência nacional e internacional que possam ser aplicadas para atendê-los. O conhecimento a respeito dessas normas e como selecionar os medidores e acessórios do sistema é de grande importância. O sistema, quando finalizado, será projetado para atender a uma série de condições pré-estabelecidas, não cabendo a sua utilização, ao menos sem a realização de uma análise profunda, em outros pontos de medição fiscal.

Palavras-chave: FPSO. Regulação. RTM. 


\section{Ajuste de dados de histórico obtidos a partir de análise de incertezas, aplicadas ao campo sintético de Tubarão Branco, com utilização de simulador comercial}

Tiago Mendes Tavares

Luis Glauber Rodrigues

Vitor Moreira da Rocha Ponte

Desafios e incertezas são constantes em todas as etapas da exploração e produção da indústria do petróleo e gás. Assim como em outros cenários do E\&P onshore, são necessários altos investimentos, desde a implantação até o abandono do campo, de modo que análises de incertezas devem ser realizadas continuamente com o intuito de identificar parâmetros que possam interferir na viabilidade do projeto. O objetivo desse estudo é ajustar o caso base (produções acumuladas de óleo, água e gás) ao histórico de produção obtido de um caso construído após análise de incertezas realizadas no campo sintético de Tubarão Branco, considerado representativo das condições reais de um campo maduro onshore, com esquema de poços do tipo five-spot, que realiza injeção de água como método de recuperação avançada. Por meio de simulador comercial (CMOST AI, CMG, 2019), que combina análise estatística avançada, aprendizado de máquina e interpretação de dados não tendenciosos, foi aplicada análise de incertezas a fim de identificar os parâmetros com maior influência na produção de óleo. Considerando os parâmetros de maior sensibilidade do reservatório, realizou-se o ajuste de histórico, levando-se em consideração que a produção de óleo histórica é maior que a obtida no caso base. Da análise de incerteza, concluiu-se que propriedades como permeabilidade relativa óleo-água, skin do poço injetor e compressibilidade das rochas resultaram em pequena sensibilidade na produção acumulada de óleo, água e gás, simultaneamente. Entretanto, parâmetros como permeabilidade horizontal, porosidade, módulo de elasticidade e skins dos poços produtores, entre outros, tiveram grande relevância na obtenção do bom ajuste das curvas de produção acumulada de óleo, água e gás. Assim, a metodologia utilizada na análise de incertezas e no ajuste de histórico foram consideradas satisfatórias para serem utilizadas nas condições desse estudo.

Palavras-chave: Análise de Incertezas. Ajuste de Histórico. Campo Maduro Onshore. Simulador Comercial. 
Arlindo Antonio de Souza

Teresa Fuess

Antonio Robson Gurgel

Fred Maia

José Alexandre

O zapGERISK é um sistema inteligente automatizado de aquisição e processamento real time de dados dos POÇOS e Instalações de Produção que usa Plataforma Digital, machine learning, aplicativos proprietários e mobile apps. A ideia é disponibilizar um sistema de informação real time confiável, ágil e flexível para apoiar os produtores de petróleo no monitoramento de suas operações, na identificação de padrões de comportamento e principalmente na antecipação de problemas. Isto deve permitir um controle adequado, menores custos e acelerar decisões. Obtidos diretamente dos sensores de campo ou carregados eletronicamente e usando a conectividade (Internet das Coisas) os dados são transmitidos, validados e armazenados numa Base de Dados fornecendo subsídios para as análises, comparações, verificações e Tomada de Decisão. Posteriormente, a plataforma permitirá ações remotas. Inicialmente serão monitoradas as variáveis: pressão, temperatura, vazão, volumes, vibração, ROP (taxa de penetração das brocas) e variações de dimensões (metrologia dimensional). Os outputs previstos nesta etapa: Módulo 01: OnLine - 1.1) PWPa (Pressure While Production), 1.2) Drill-of Test (otimização da perfuração); Módulo 02: ANP 2.1) Atendimento: SGI, SGIP, RTDT, SGSO, carga de dados ANP, 2.2) SGIP Integrado; Módulo 03: Gestão PROATIVA - 3.1) PetroNEG simulator (capacitação e treinamento), 3.2) EVTEASp (mitigação dos riscos e incertezas), 3.3) FMECAevte da Inovação (Innovations Business Plan), 3.4) PMO Smart Track (foco no portfólio e na agilidade operacional) e 3.5) Desinvestimento, Revitalização e Descomissionamento; Módulo 04: PDSI - 4.1 Smart as Built (como previsto e como executado), 4.2) QualiTEC (previsibilidade), 4.3) Manutenção PROATIVA (disponibilidade), 4.4) Kick sem Blowout (segurança operacional), 4.5) REVAMP, Unitização e Abandono (Integridade).

Palavras-chave: zapGERISK. Produção de petróleo e gás, automação. Real time. Pressure while production. SGIP Integrado. Atendimento ANP. PetroNEG simulator. 


\section{Acoplamento iterativo explícito fluxo-geomecânica de reservatório trifásico com black-oil}

Yuri Nunes Saraiva

Moacir Frutuoso Leal da Costa

Emanuelle Fernandes Braga

Francisco Helson de Lima Neres

Luis Glauber Rodrigues

A simulação por análise numérica para cenários de engenharia de reservatórios é necessária devido à grande importância de se prever e antecipar as consequências e produtos de uma explotação de água ou petróleo, bem como à vasta quantidade de variáveis que estão associadas à engenharia hidráulica, de petróleo e à geomecânica das rochas. Devido a isso, o presente trabalho consiste na apresentação de atividades relativas ao acoplamento de geomecânica e simulação de fluxo baseados no problema 4 do paper SPE - 79709, de autoria de Dean et al. (2006), problema esse que apresenta um reservatório trifásico com black-oil e um poço injetor de água e outro poço produtor, em lados diametralmente opostos. O software utilizado para o acoplamento fluxo-geomecânico é o simulador IMEX, versão 2019, em acoplamento iterativo explícito. A metodologia inclui a criação de dois cenários, um sem geomecânica aplicada e outro com fluxo-geomecânica acoplados. Os resultados demonstram a obtenção de convergência satisfatória entre os resultados do modelo de fluxogeomecânica acoplado ao problema proposto por Dean et al. Assim, ao final da simulação, de 9.125 dias, obteve-se pressão média final do reservatório de 1.504,32 psi e subsidência, no topo da região central do reservatório, de 4,22ft, parâmetros esses apresentados no paper proposto, bem como parâmetros de razão de óleo, razão gás-óleo, razão água-óleo, saturação de água e pressão no fundo do poço obtidos exclusivamente pelo modelo acoplado. A importância dessa metodologia em se considerar o acoplamento fluxogeomecânica traz grandes melhorias no gerenciamento de projetos de produção de petróleo, visto que há correção no valor da pressão média, nos resultados de produção e informação de subsidência que pode afetar a infraestrutura de produção.

Palavras-chave: Acoplamento Iterativo. Análise Numérica. Fluxo-Geomecânica. Subsidência e black-oil. 


\title{
18 Inteligência artificial versus método assistido: diferenças e oportunidades na análise de incertezas e ajuste de histórico em reservatório onshore com injeção de $\mathrm{CO}_{2}$
}

\author{
Francisco Helson de Lima Neres \\ Emanuelle Fernandes Braga \\ Yuri Nunes Saraiva \\ Tiago Mendes Tavares \\ Luis Glauber Rodrigues
}

O engenheiro de reservatórios realiza trabalhos que buscam honrar os dados de produção dos reservatórios. Para auxiliar nessa tarefa, utilizam-se de técnicas de ajuste assistido/manual, e, mais recentemente, ferramentas de inteligência artificial disponíveis em softwares comerciais utilizados no setor de exploração e produção de hidrocarbonetos. Este estudo é realizado em um modelo de reservatório de características onshore que tem como fluido injetante o $\mathrm{CO}_{2}$. O objetivo do estudo é comparar o potencial da análise de incertezas e ajuste de histórico entre duas metodologias: na primeira aplica-se o método de ajuste assistido e na outra utiliza-se o software comercial da $\mathrm{CMG}^{\circledR}, \mathrm{o} \mathrm{CMOST}^{\circledR}$. Os parâmetros estimados para o ajuste são as produções acumuladas de óleo e gás. Ao fim, espera-se observar as diferenças e as vantagens de um método em relação ao outro. Os dados de histórico de produção são oriundos do refinamento do modelo-base. O modelo-refinadometa foi aquele cuja diferença entre os resultados de produção acumulada de óleo, dos níveis refino, é igual ou menor que $1 \%$. No ajuste assistido, os pontos de máximo das curvas de permeabilidade são alterados e seus resultados são comparados ao do modelo-refinadometa. No outro método, o ajuste de histórico é auxiliado pelo software comercial, que, por sua vez, apresenta um leque de resultados de produção possíveis, dados os parâmetros escolhidos na etapa de análise de incertezas. Os resultados mostrarão as diferenças entre a precisão de cada técnica. Os dados de produção gerados irão convergir minimamente aos resultados-meta no ajuste de histórico, embora ainda seja perceptível a dificuldade no encontro de um resultado único-comum que dê exatidão aos valores de produção parametrizados. Assim, é possível concluir que o ajuste assistido pode ser ferramenta norteadora para a escolha dos parâmetros dentro do ajuste realizado pelo $\mathrm{CMOST}^{\circledR}$, além da perceptível otimização no processo de análise de incertezas do modelo.

Palavras-chave: Reservatório. Simulação. $\mathrm{CO}_{2}$. Ajuste de histórico. Curva de permeabilidade. 


\title{
19 Comparação de métodos de recuperação por injeção de $\mathrm{CO}_{2}$ ou água sob diferentes perspectivas de refino de grid em reservatório de características do onshore brasileiro
}

\author{
Francisco Helson de Lima Neres \\ Pablo Fernandes Marques \\ Yuri Nunes Saraiva \\ Tiago Mendes Tavares \\ Luis Glauber Rodrigues
}

Se comparados com o pré-sal, os campos maduros do onshore brasileiro não possuem altos volumes de produção, contudo esses campos se revelam como alternativa viável para a exploração de pequenas e médias empresas do setor. Desse modo, os estudos acerca de saídas viáveis que otimizem a produção desse hidrocarboneto são indispensáveis para a manutenção da dinâmica de produção no setor. Este estudo é realizado em um modelo de reservatório que possui heterogeneidades tanto na porosidade quanto nas permeabilidades. A disposição dos poços é em five-spot invertido. O objetivo do estudo é comparar os efeitos na produção de óleo, gás e água quando o reservatório recebe fluidos diferentes na injeção e encontra-se em condições diferentes de refino de grid, pelos seguintes parâmetros: tempo de breakthrough, fator de recuperação e comportamento da saturação do óleo dentro do reservatório e tempo de simulação. A metodologia aplicada ao trabalho consiste no posicionamento do modelo em dois cenários: injeção de $\mathrm{CO}_{2}$ e injeção de água. Esses cenários irão passar pelos mesmos designs de refinamento. Após a simulação, esses modelos serão comparados dentro dos parâmetros elencados no objetivo do estudo. Os resultados mostrarão que o reservatório apresenta resultados díspares quando comparados os modelos de injeção. O refino auxilia na percepção da dinâmica de fluxo no reservatório, contudo aumenta o tempo de análise por afetar diretamente o tempo de simulação dos casos. Os perfis dos mapas de saturação sustentam que a escolha do fluido é vital para o retardamento do tempo de breakthrough no reservatório. Desse modo, foi possível concluir que a metodologia que leva à pura injeção de água pode não ser o método mais eficaz para a produção desse reservatório. Abre-se ainda um leque de oportunidades quanto a futuras análises de metodologias, podendo-se utilizar ferramentas de inteligência artificial, como é o caso do $\mathrm{CMOST}_{\mathrm{CMG}}{ }^{\circledR}$, que viabilizam uma gama maior de possíveis soluções.

Palavras-chave: Reservatório. Simulação. Água. $\mathrm{CO}_{2}$. Refino. Saturação de óleo. 


\section{Avaliação de correlações empíricas para o cálculo do fator de $\mathbf{m}$ compressibilidade de gás natural de campos brasileiros

Gabriel Souza do Lago

Frederico Ribeiro do Carmo

Várias correlações para propriedades de fluidos de reservatório são encontradas na literatura, porém, a escolha que mais se adequa ao reservatório a ser estudado depende fortemente do tipo de formação em que o fluido em questão está localizado. A escolha da correlação adequada para uma dada propriedade de um fluido de reservatório é uma tarefa minuciosa e está diretamente ligada à qualidade dos resultados que serão obtidos nas simulações de reservatório. Neste sentido, o objetivo deste trabalho foi avaliar diversas correlações empíricas para o cálculo do fator de compressibilidade de gás natural de campos brasileiros. Ao todo, foram avaliadas 19 correlações, as quais foram obtidas na literatura aberta. Para a realização do trabalho, um código Python foi desenvolvido. Dados experimentais de quatro amostras de gás natural oriundas de campos brasileiros foram utilizadas na avaliação. $O$ critério de avaliação foi a média dos desvios absolutos (MDA). Baseado neste critério, os melhores métodos foram os de Al-Anazi, Bandar Duraya et al. (2010) (ABD 2010), Heidaryan, Moghdasi and Salarabardi (HHS) e Kareem, Iwalewa and Al-Marhoun (KIA), os quais apresentaram MDAs iguais a 1,84\%, 3,57\% e 5,11\%, respectivamente. As correlações possuem faixas de aplicação para temperatura pseudo-reduzida (Tpr) e pressão pseudoreduzida (Ppr), que são: (1.2<= Tpr <= 3.0) e $(0.2<=\operatorname{Ppr}<11),(1.2<=\operatorname{Tpr}<=3.0)$ e $(0.2<=$ Ppr $<=15)$ e $(1.15<=\operatorname{Tpr}<=3.0)$ e $(0.2<=\operatorname{Ppr}<15)$, respectivamente. Observou-se que, para uma escolha mais adequada do método a ser utilizado, é importante considerar as condições de temperatura e pressão, bem como a composição de contaminantes no gás.

Palavras-chave: Gás natural. Fator de compressibilidade. Correlações. Python. 


\section{Estudo da solubilidade e caracterização de solvente aplicado como líquido dessecante para absorção da água presente no gás natural}

Mylla Monteiro Albuquerque

Carla Vanessa Dias Guimarães

Paulo Henrique Alves de Azevedo Geraldine Angélica Silva da Nóbrega

A desidratação do gás natural, via absorção gasosa utilizando líquido dessecante, é uma solução comprovada e corresponde a um método robusto para remover o excesso de umidade. Estes sistemas empregam um meio higroscópico que pode absorver umidade em pressões de vapor abaixo da pressão de saturação de água pura. A pesquisa na área de microemulsão inversa, à base de tensoativos não iônicos, surge nesta realidade como uma inovação, procurando desenvolver um dessecante líquido estável que ofereça alta eficiência no que diz respeito à desidratação do gás natural por meio da absorção gasosa. Dessa forma, no presente projeto, realizou-se a formulação e caracterização de dessecantes líquidos no que confere: massa específica, miscibilidade, estabilidade, viscosidade e condutividade. Neste contexto, o comportamento de fases para misturas ternárias formadas por hidrocarboneto/tensoativo não iônico/água foi estudado em três diferentes proporções de misturas de hidrocarbonetos ao longo de uma linha de diluição de água com uma proporção de 40:60\% tensoativo não iônico/fase oleosa, à temperatura de $25{ }^{\circ} \mathrm{C}$, com base em diagramas de fases construídos. A região de microemulsão foi determinada por titulação de acordo com o limite de solubilidade de cada sistema. Por meio do cálculo integral, determinou-se a área da região microemulsionada para os sistemas estudados e foi verificado que o sistema ÁGUA/UNP 60/QUEROSENE:HEXANO (1:3) apresentou maior área da região de microemulsão. A fim de caracterizar o comportamento da microemulsão, foi investigada a condutividade elétrica. À medida que a fração de volume de água aumenta na mistura, um limiar de percolação é observado, e isto é determinado quando a condutividade elétrica aumenta.

Palavras-chave: Gás natural. Desidratação. Microemulsão. 


\section{Efeito da temperatura na cimentação de poços petrolíferos}

Júlio Cezar de Oliveira Freitas

Rodrigo César Santiago

Bruno Leonardo de Sena Costa

Fabricio Pereira Feitoza da Silva

Paulo Henrique Silva Santos Moreira

A cimentação primária tem um papel fundamental na integridade do poço, pois ela estabelece o isolamento hidráulico entre as formações rochosas e o poço, garantindo a estabilidade mecânica e proteção do revestimento contra corrosão. Em poços com elevadas temperaturas $\left(>110{ }^{\circ} \mathrm{C}\right)$, sejam eles naturalmente aquecidos ou quando submetidos aos métodos de recuperação térmica (injeção de vapor), devem ser aplicados sistemas de pastas de cimento com relação Ca/Si próxima a 1 para garantir a estabilidade dos produtos das reações de hidratação. Sendo assim, o presente trabalho tem como objetivo avaliar o efeito da temperatura em pastas de cimento destinadas a poços petrolíferos. Foram preparados dois sistemas de pasta, sendo um deles padrão, sem adição de sílica flour (SSF), e outro sistema contendo $40 \%$ de sílica flour (CSF). As pastas foram preparadas de acordo com a API $\mathrm{RP}$ 10B. Foram realizados ensaios de resistência à compressão (RC) e Difração de raios-X (DRX). Os resultados de RC mostraram uma redução significativa da resistência da pasta SSF em relação à pasta CSF. Os difratogramas evidenciaram silicatos instáveis (?C2SH), responsáveis pela baixa RC da pasta sem sílica flour e fases estáveis (Xonotlita) na pasta CSF. Sendo assim, pode-se concluir que o uso de sílica flour é fundamental para a manutenção da resistência à compressão da matriz de cimento em poços com temperaturas superiores a 110 oc.

Palavras-chave: Cimentação. Alta temperatura. Sílica flour. 


\title{
23 Otimização do fator de recuperação de óleo para um campo maduro aliado ao armazenamento de dióxido de carbono

\author{
Antonio Gladstone Pereira de Matos \\ Tiago Mendes Tavares
}

\begin{abstract}
A demanda de petróleo mundial segue crescente nos últimos anos, e, com ela, a necessidade de suprir tal demanda e viabilizar a exploração de campos maduros para recuperação de óleo residual. Para viabilizar a produção de um campo maduro onshore sintético escolheu-se a estratégia de reinjeção de dióxido de carbono $\left(\mathrm{CO}_{2}\right)$, funcionando como método de recuperação avançada de óleo e como instrumento de mitigação da emissão desse tipo Gás de Efeito Estufa (GEE). Este estudo tem como objetivo entender o potencial de produção do campo maduro para então traçar uma estratégia de otimização de recuperação do óleo aliado à maximização do armazenamento de $\mathrm{CO}_{2}$. A metodologia adotada para este projeto baseouse na utilização de softwares de simulação de reservatórios da CMG (Computer Modelling Group Ltda) para a modelagem do fluido de reservatório, simulações numéricas de fluxo contínuo para o modelo composicional e otimização tanto do fator de recuperação de óleo quanto do sequestro de $\mathrm{CO}_{2}$. Desta forma, o presente trabalho proporciona uma visão do comportamento do método $\mathrm{CO}_{2}$-EOR (Carbon Dioxide Enhanced Oil Recovery) e sua influência sobre o fator de recuperação de óleo do reservatório estudado. Além disso, a partir dos resultados obtidos, é possível concluir que o tipo de completação, as vazões de injeção e produção, e, principalmente, a composição do gás de injeção, têm papel importante na otimização do fator de recuperação de óleo e no armazenamento do $\mathrm{CO}_{2}$.
\end{abstract}

Palavras-chave: Reinjeção. Simulação. Residual. 


\section{Realização de análise PVT em amostra sintética de derivados de petróleo}

Este trabalho teve como objetivo principal a realização de análise PVT para determinação das propriedades fator volume formação do óleo, pressão de bolha e razão de solubilidade em amostra sintética de heptano e gás metano - inicialmente a mistura foi submetida à pressão de 450 bar e temperatura de $80^{\circ} \mathrm{C}$. A análise foi realizada na célula PVT Fluid Eval Educacion, da VINCI TECHNOLOGIES, obedecendo uma liberação à massa constante (Flash). A análise foi conduzida à temperatura constante, provocando o declínio da pressão inicial de 450 bar até alcançar a pressão atmosférica, seguindo os seguintes critérios de estabilidade: (tempo de agitação: 1 minuto; pressão: 2 bar; temperatura: 0,5 ㅇ; variação de volume: 0,20 cm3). Os resultados obtidos contemplam a pressão de bolha, que foi de 182,79 bar, fator volume de formação do óleo (Bo) no valor de $1.72 \mathrm{~cm}^{3} / \mathrm{cm}^{3}$ e a razão de solubilidade no valor de 242.30 $\mathrm{cm}^{3} / \mathrm{cm}^{3}$. Os resultados obtidos também foram representados sob forma gráfica da propriedade observada em função da pressão, os quais se mostraram coerentes e satisfatórios.

Palavras-chave: Análise. Flash. Pressão de bolha. Compressibilidade. 


\title{
25 Xisto Betuminoso: uma Alternativa Energética
}

\author{
Isadora Cristina Bezerra do Nascimento \\ Giulia Ranelly da Silva Costa \\ Edney Rafael Viana Pinheiro Galvão
}

O xisto betuminoso começou a ser estudado em 2009, nos EUA, possibilitando uma nova fonte de energia alternativa para a economia americana. Por ter uma vasta reserva de gás xisto, o país pode se tornar energicamente independente, já que ele é um dos maiores consumidores de petróleo importado. Isso despertou um forte interesse brasileiro em explorações do gás xisto, pois no Paraná existe a maior fonte de xisto betuminoso. Além de ter qualidade semelhante ao gás natural, o gás a partir do xisto é capaz de reduzir economicamente altos gastos com energia, sendo ele viável para consumo de indústrias, residências e outros.

Palavras-chave: Energia. Independente. Exploração. Xisto. Reduzir. 


\section{Caracterização de argila atapulgita aplicada a fluidos de perfuração}

não aquosos

lane Barbosa Augusto dos Santos

Com os grandes desafios advindos da perfuração de poços, surge a necessidade de desenvolvimento ou modificação de fluidos cujas propriedades são capazes de atender às exigências de perfuração. Devido a isso, o estudo com argilas vem sendo desenvolvido cada vez mais, uma vez que estas apresentam propriedades como a capacidade de inchamento, alta capacidade de troca iônica, além de forte capacidade de adsorção. Para a obtenção de resultados favoráveis, faz-se necessário modificar a argila para que esta tenha papel fundamental na preparação do fluido de perfuração. Os fluidos de perfuração não aquosos foram desenvolvidos para perfurações com condições de alta temperatura e elevada pressão, aspectos comuns em perfurações direcionais, o que gera limitação para os fluidos aquosos. Esse trabalho teve por objetivo modificar a argila atapulgita, com o intuito de aumentar sua afinidade pela fase orgânica de fluidos de perfuração não aquosos, aplicando um tensoativo do tipo catiônico em uma concentração pré-estabelecida. As medidas de ângulo de contato apontaram um aumento da característica hidrofóbica da atapulgita modificada. No contexto da análise reológica, a atapulgita organofilizada apresentou propriedades reológicas semelhantes a uma argila organofilizada comercial.

Palavras-chave: Fluido de perfuração. Atapulgita. Adsorção. 


\section{Coletores solares para preaquecimento de água em Reservatórios de óleo Pesado}

Sergio Romero Galvão Sales Junior

Os métodos de recuperação secundária são essenciais para a produção de petróleo quando o reservatório não possui pressão suficiente para que o óleo chegue à superfície. Diante deste problema surge a necessidade do desenvolvimento de novas tecnologias para suprir a pressão do reservatório, de maneira que o poço possua sua produção viável. O estudo em questão consiste em adaptar um sistema já existente, no caso as caldeiras, que aquecem a água transformando-a em vapor. A finalidade deste vapor é diminuir as forças viscosas ao entrar em contato com o óleo no reservatório para que este possa escoar chegando à superfície. Um grande problema desse sistema já existente é a quantidade de combustível requerida, o que gera também uma liberação de gases poluentes na atmosfera. Devido a isso, a aplicação de coletores solares, se colocado antes da caldeira a fim de aquecer a água antes de entrar na caldeira, proporciona a diminuição da quantidade de combustível necessária. 0 consumo de combustível anual sem coletor é de aproximadamente $\mathrm{R} \$ 40.808 .966,87 \mathrm{~m}^{3}$ /ano, com aplicação do coletor há uma economia de cerca $\mathrm{R} \$ 644.961,47$ por ano. A duração média de injeção dura em torno de 10 anos, então o valor economizado é próximo de R\$ 6.449.614,7. Diante do exposto, acredita-se que o consumo de combustível com uso de coletores será reduzido em $\mathrm{R} \$ 40.164 .005,40 \mathrm{~m}^{3}$ /ano. Embora haja o custo com coletor de $\mathrm{R} \$$ 871.859,25 para esse caso, ele apresenta a vantagem de possuir durabilidade de 25 anos. Averiguando o valor dos gastos e o valor da economia que o projeto apresenta, é possível concluir que a aquisição torna-se viável. O campo de estudo utilizado foi na Bacia de Potiguar, em Alto do Rodrigues, utilizando uma temperatura de entrada de $30^{\circ} \mathrm{C}$ e saída de $60^{\circ} \mathrm{C}$. O projeto pode ser ainda menos dispendioso, dependendo da localidade em que é aplicado.

Palavras-chave: Coletor solar. Óleo Pesado. Preaquecimento. 


\title{
28 Avaliação de correlações de translação de volumes acopladas à equação cúbica de Peng e Robinson para predição do volume molar de hidrocarbonetos
}

\author{
Maxwell Risseli Laurentino da Silva \\ Alanderson Arthu Araújo Alves \\ Vitor Pette Kovet Pereira \\ Ferreira, Frederico Ribeiro do Carmo
}

A densidade é uma variável fundamental para cálculos de reservatórios de petróleo, sendo as equações cúbicas propostas por Peng-Robinson (PR) e Soave-Redlich-Kwong (SRK) OS principais modelos utilizados em simuladores do tipo composicional. No entanto, tais equações não predizem de maneira satisfatória a densidade da fase líquida. Com o intuito de corrigir este problema, em 1982, Péneloux e colaboradores propuseram o conceito de translação de volume, no qual o volume molar é subtraído por um fator de correção. É prática comum entre os engenheiros de reservatório a estimativa do volume de translação, também conhecido como volume shift, a partir da regressão de dados experimentais dos fluidos do reservatório a ser estudado. Apesar de ser comum, deve-se ter cautela ao realizar esta prática, pois valores sem sentido físico podem ser obtidos para outras propriedades funções da densidade, como a velocidade do som e a capacidade calorífica isobárica. Objetivando a obtenção de valores de translação de volume mais seguros, diversas correlações foram sugeridas nos últimos anos. No presente trabalho, avaliou-se as correlações para a translação de volume propostas por Jhaveri e Youngren (1988), Ungerer e Batut (1997) e Le Guennec et al. (2016), aplicadas a 27 hidrocarbonetos de diversas classes (alifáticos, cíclicos e aromáticos). Tais correlações foram acopladas à equação de Peng-Robinson. Baseado na média dos desvios relativos absolutos (MDRA), os resultados obtidos foram: 2,08\% para o método proposto por Guennec et al. (2016), 3,04\% para Jhaveri e Youngren (1988) e 9,35\% para Ungerer e Batut (1997). É importante mencionar que o método de Jhaveri e Youngren (1988) não foi capaz de estimar valores para alcanos insaturados, alcenos e alcinos.

Palavras-chave: Equação cúbica. Volume molar. 


\section{Tratamento de águas produzidas de exploração petrolífera}

contaminadas com sulfetos

Sarah Rayanne de Lima Silva

Eduarda Ticiana Rocha de Oliveira

Edney Rafael Viana Pinheiro Galvão

As águas produzidas são misturas complexas, contendo muitos contaminantes, como óleo finamente disperso, metais pesados e gases como $\mathrm{H}_{2} \mathrm{~S}$ e $\mathrm{CO}_{2}$, originados da exploração de petróleo e gás natural. $\mathrm{O} \mathrm{H}_{2} \mathrm{~S}$ é um gás altamente tóxico, potencialmente letal e quando nas águas produzidas, pode formar um ácido corrosivo nas tubulações, nas linhas de fluxo e outros equipamentos. A concentração de sulfetos nessas águas, para descarte no ambiente, tem que ser menor que 0,3ppm (CONAMA), e petróleo, 20 ppm. Os processos de exploração de petróleo estão associados com águas produzidas. O volume de água produzida obtida oriundo dos campos de petróleo depende de fatores como: estrutura geológica da formação, práticas de produção e tempo de produção dos fluidos do reservatório (BAYATI; SHAYEGAN; NOORJAHAN, 2011). Estes efluentes se constituem de misturas complexas de materiais orgânicos e inorgânicos, suspensos e dissolvidos, juntamente com metais pesados (MORAES; PAULO; MEDEIROS, 2011). Neste trabalho, utilizou-se extração por solvente para remoção das espécies sulfetadas e petróleo. Utilizaram-se três aminas comerciais (alquil) como extratantes, dissolvidas em querosene de aviação (combustível de avião). A eficiência do processo de extração foi avaliada em termos de concentração (ppm) de $\mathrm{H}_{2} \mathrm{~S}$ e óleo, antes e depois do contato entre as fases. É proposto um processo onde os contaminantes são separados dos efluentes através do processo de extração líquido - líquido em regime de batelada, onde os constituintes misturados à fase aquosa (petróleo e $\mathrm{H}_{2} \mathrm{~S}$ ) migram preferencialmente para a fase oleosa após ação do solvente extratante, uma mistura de Querosene de Aviação ( $Q A V)$ e aminas. Concluiu-se que a melhor eficiência de extração ocorreu com a amina Duomeen 0 , que obteve $76 \%$ de remoção de sulfetos; em segundo aparece a amina ARCUAD 2c-75, mostrando 59\% de eficiência de remoção, e a amina DUOMEEN T, que apresentou 40\% de remoção.

Palavras-chave: Petróleo. Sulfetos. Tratamento de água. 
30 Revestimento de polietileno de alta densidade (PEAD) como sistema de proteção contra corrosão em oleodutos no RN

Thiago Ticiano Aires de Araújo Andrea Francisca Fernandes Barbosa Jardel Dantas da Cunha

A estrutura brasileira de abastecimento de petróleo, gás e derivados, interligada às fontes de produção, refinarias e centros de consumo, baseiam-se principalmente na malha dutoviária do país. Grande parte dessa malha é, até o momento, operada pela Petrobras ou Transpetro, na qual uma parcela altamente significativa (em torno de 77\%) de sua extensão é constituída por dutos com mais de 20 anos de operação. Estudos realizados têm mostrado que os dutos de transporte em atividade no país apresentam sérios problemas de corrosão interna e/ou externa, e formação de depósitos tanto orgânicos como inorgânicos. A extensão e gravidade destes problemas estão relacionadas ao tipo de produto transportado, condições de operação e localização, implicando em manutenção periódica destes. O revestimento interno para tubulações de condução de petróleo, gás, água, etc., fabricado em tubos de polietileno de alta densidade (PEAD) para protegê-las contra a corrosão/abrasão é denominado Liner. 0 presente estudo foi realizado em dois oleodutos com extensões médias de $20 \mathrm{~km}$ e produções diárias de $5000 \mathrm{bbl} /$ dia e $3500 \mathrm{bbl} / \mathrm{dia}$, sendo em ambos os casos realizados estudos técnicos e econômicos em três cenários: reabilitação com aplicação do revestimento de PEAD, construção de um novo duto e transporte por carretas-tanques. Resultados apontam que caso a opção de transporte da produção por meio de carretas-tanques ocorra durante 2 anos, as despesas seriam compatíveis com o custo de reabilitação do duto com inserção do revestimento de PEAD para ambos os dutos. Após 3 (três) anos, os custos com transporte de carreta-tanque ultrapassam o investimento para inserção do liner, enquanto no quarto ano os valores envolvidos são praticamente equivalentes ao custo de fabricação de um novo duto em aço com as mesmas características do anterior.

Palavras-chave: Revestimento. PEAD. Corrosão. 


\section{Análise de integridade por elementos finitos de compósito polimérico tripla camada aplicado em tubulações de petróleo}

Italo M. Gomes, Alex A. S. Silva

Rodrigo Nogueira de Codes

A indústria do Petróleo e Gás e seus campos maduros têm constantemente se deparado com problemas de corrosão em equipamentos, devido à caraterística química do petróleo, do gás e dos contaminantes nos reservatórios. Os compósitos são materiais muito promissores para mitigar esse problema, por somarem boas propriedades mecânicas e térmicas, com excelente resistência à corrosão, pois são compostos de mais de um material, aproveitando as propriedades destes. Em 2010 foi desenvolvido um compósito tripla camada para tubulações de produção de poços terrestres de petróleo como alternativa ao aço API 5L Grau B, comumente utilizado e mais suscetível à corrosão. No presente trabalho coletou-se amostras de tubos desse compósito em tubulações de três poços de petróleo de três áreas distintas no estado do Rio Grande do Norte, que operam com esse material há alguns anos. As amostras foram analisadas por ensaio de tração, a fim de avaliar as propriedades e a integridade do material em condições operacionais reais de campo e compará-los com os resultados de uma simulação computacional utilizando o método de elementos finitos. Os resultados dos ensaios de tração mostraram uma variação nas propriedades mecânicas, principalmente da amostra controle, fato que pode ser justificado pelas diferenças de espessuras das camadas das amostras e dificuldade de controle de qualidade e a anisotropia dos materiais compósitos. A simulação por elementos finitos comprovou que uma variação nas espessuras das camadas provoca uma alteração nas propriedades do material. Esses resultados evidenciam a necessidade de melhoria no controle de qualidade dessas tubulações durante a fabricação, a fim de evitar falhas que possam causar prejuízos financeiros ou acidentes ambientais e pessoais.

Palavras-chave: Tubulação de Produção. Compósito. Elementos Finitos. Ensaios Mecânicos. 


\title{
32 Análise de viabilidade econômica da injeção de $\mathrm{CO}_{2}$ em $\boldsymbol{n}$ reservatórios maduros
}

\author{
Ricardo Henrique de Andrade Galvão Junior \\ Edney Rafael Viana Pinheiro Galvão \\ Francisco Samuel Portela de Albuquerque
}

A mudança climática oriunda do aumento da taxa de emissões antrópicas dos gases do efeito estufa é uma das principais preocupações ambientais. O Dióxido de Carbono $\left(\mathrm{CO}_{2}\right)$ é um dos principais gases do efeito estufa, e diversas tecnologias têm sido desenvolvidas para sequestrar $\mathrm{O}^{\mathrm{CO}_{2}}$ antes da sua emissão na atmosfera, entre elas tem-se as tecnologias de: absorção, adsorção, separação por membranas semipermeáveis, separação criogênica e o "looping químico" (BELLO; MUSTAFA, 2010). A injeção de $\mathrm{CO}_{2}$ em poços de petróleo para recuperação avançada de petróleo se enquadra como um processo terciário, onde a finalidade do método é que o fluido injetado (fluido deslocante) empurre o óleo (fluido deslocado) através dos poros das rochas, ocupando o espaço anteriormente do petróleo (OLIVEIRA, 2016). Ferreira da Silva (2007) fez um estudo de viabilidade econômica em um poço maduro no recôncavo baiano com estimativa de análise de produção de 20 anos. 0 fluxo de caixa foi estimado com as seguintes suposições: receitas de óleo são baseadas nas condições do mercado, créditos de $\mathrm{CO}_{2}$ e custos do projeto - tais como custos fixos operacionais (OPEX), custos operacionais variáveis, custos de capital com tratamento de $\mathrm{CO}_{2}$, compressão, transporte, armazenamento, impostos como imposto de renda, PIS/COFINS e fatia governamental. O payback de investimento foi de 6 anos de operação, o VPL seria de 13,95 milhões de dólares e com os créditos de $\mathrm{CO}_{2}$ de 16,67 milhões. Considerando o desconto de impostos, fica 6,98 milhões de dólares, e inserindo os créditos de carbono tornase 7,84 milhões de dólares. Com o apuramento dos dados, é possível concluir que o principal obstáculo para a implantação do método é o alto custo para processos de sequestro de $\mathrm{CO}_{2} \mathrm{e}$ leis governamentais para incentivo de créditos de carbono. O preço do barril de petróleo também é um dos fatores que podem influenciar na viabilidade do projeto. Ademais, o processo é economicamente viável a longo prazo.

Palavras-chave: Recuperação avançada. Gás carbônico. Petróleo. 


\section{Análise de molhabilidade em rocha calcária do RN com adsorção de tensoativo aniônico}

Kidja Maria Ramalho Frazão Gerbeson Carlos Batista Dantas Ana Paula Brito de Almeida Patrícia Mendonça Pimentel Vanessa Cristina Santanna

Desenvolvimento de tecnologias para maior aproveitamento do petróleo é a temática abordada neste projeto, cujo objetivo é determinar a molhabilidade da rocha extraída da microrregião de Baixa Verde no Rio Grande do Norte, uma vez que a predominância na rocha reservatório é do tipo carbonática. Sendo assim, estudamos a adsorção do tensoativo aniônico chamado Óleo de Coco Saponificado (OCS) na amostra de calcário magnesiano e realizamos ensaios em banho finito para análises de tensão superficial e ângulo de contato. Em suma, a análise do filtrado pelo equipamento SensaDyne Tensiometer (QC6000/método pressão máxima de bolha/nitrogênio) quanto à tensão superficial indicou cerca de 59,3 dynes/cm, e comparada à solução de OCS (36,1 dynes/cm) foi possível observar que houve adsorção. Ademais, comprovou-se também a efetiva adsorção devido ao ponto de referência (água), que foi medido a $29,7^{\circ} \mathrm{C}$, equivalendo a 72,4 dynes/cm. Para a análise de ângulo de contato utilizamos o goniômetro Krüss (DAS100) com o auxílio do software DAS3, onde o corpo de prova em formato de pastilha com tensoativo obteve 96,9 e in natura 19,8, o que corrobora para molhabilidade mista a amostra com calcário magnesiano após banho finito acrescido do tensoativo aniônico. Com isso, observa-se que a amostra de calcário magnesiano apresenta bom desempenho na adsorção do tensoativo OCS por possuir carga negativa na parte polar, reagindo eletrostaticamente com os íons da rocha. E sua molhabilidade é mista, ou seja, o óleo se torna contínuo nos poros maiores e a água nos menores, de acordo com a afinidade do fluido. Portanto, nas operações de recuperação do petróleo em reservatório, o método químico que abarca tensoativo é uma estratégia de estudo crescente.

Palavras-chave: Molhabilidade. Adsorção. Rocha calcária. Tensoativo. 


\section{Aplicação de resina em poços de petróleo}

Willame G. S. Batista

Júlio C. O. Freitas

Yvis H. Oliveira, Filipe Oliveira

No Brasil, muitos poços de petróleo estão perto do final de sua vida útil e serão abandonados, outros poços necessitarão de operações de correção após apresentarem falhas na cimentação. As operações de abandono e correção são realizadas, habitualmente, com cimento Portland com o propósito de tornar o poço seguro tanto quanto à segurança operacional quanto ao meio ambiente. Visando manter estes propósitos, a resina surge como um material alternativo ao cimento. Há casos de aplicação de resina para isolamento de poços de petróleo, pois possui maior resistência à compressão, tração e cisalhamento, além de maior poder de penetrabilidade, que está associado ao seu comportamento de fluido newtoniano. Ela pode ser aplicada como substituta total ou parcial ao cimento. A utilização como substituinte total é normalmente recomendada para correções como preenchimento de micro canais por ter alta taxa de penetrabilidade e baixo teor de sólido, no entanto também é recomendada para abandono de poços em que se pode utilizar um pequeno volume de material para operação, uma vez que é um material de alto valor, e a relação custo-benefício deve ser avaliada, pois uma das alternativas à aplicação em operação de abandono é utilizar a resina como substituinte parcial ao cimento, visto que o cimento está presente na composição. A resina como fase principal e o cimento como um aditivo sólido. Em suma, a resina é um material alternativo com grande potencial para aplicação em larga escala nas operações citadas e com grande probabilidade de desenvolvimento de novos sistemas para um maior número de operações.

Palavras-chave: Resina. Cimento. Abandono. Correção. 


\title{
35 Predição da velocidade do som de hidrocarbonetos nas fases líquida e vapor utilizando as equações cúbicas de Soave-Redlich- Kwong e Peng-Robinson
}

\author{
Maxwell Risseli Laurentino da Silva \\ Alanderson Arthu Araújo Alves \\ Frederico Ribeiro do Carmo
}

Desde meados do século $X X$, as equações cúbicas de estado desempenham papel fundamental na indústria química, por se tratar de modelos de fácil utilização e vasta aplicabilidade, sendo as equações cúbicas propostas por Peng-Robinson (PR) e Soave-RedlichKwong (SRK) as utilizadas com maior frequência para a estimativa de propriedades termodinâmicas. Neste sentido, no presente trabalho foi realizada uma avaliação das equações de SRK e PR para a predição da velocidade do som de líquido e vapor saturados de hidrocarbonetos. Em engenharia de petróleo, esta propriedade possui utilidade na determinação do nível de óleo e/ou gás em reservatórios e é aplicada também para estimar o fluxo de volume real do gás em medidores de vazão ultrassônicos. No total, foram avaliados 25 hidrocarbonetos em suas respectivas temperaturas de saturação entre a temperatura do ponto triplo e a temperatura crítica. As equações estudadas não apresentaram resultados satisfatórios para predizer a velocidade do som, principalmente para a fase líquida, uma vez que os desvios médios relativos absolutos (DMRA) foram, para a fase vapor, iguais a 9,06\% para SRK e 8,63\% para PR, respectivamente. Enquanto para a fase líquida foi de $20,31 \%$ para SRK e 19,15\% para PR, respectivamente.

Palavras-chave: Equações de Estado. Velocidade do Som. Reservatórios. 


\title{
36 Otimização na perfuração de poço onshore de alta instabilidade no Recôncavo Baiano utilizando-se nanotecnologia e motor direcional de alta performance
}

\author{
Adelson Belizário Leal \\ Alexandre de Lima Barroso \\ Lillian Maronezi \\ Luis Flores \\ Ubiratan Santos
}

A instabilidade mecânica no processo de construção de poços se caracteriza como um conhecido problema. Nano-fluidos podem ser produzidos por adição de partículas nanométricas em baixa concentração. Nanopartículas promovem características reológicas, mecânicas, ópticas e térmicas ao fluido. Associado a estudos de laboratório, foi desenvolvido e customizado um sistema de fluido base nanotecnologia para aplicação no cenário onshore do Brasil. O sistema foi utilizado na perfuração de formações instáveis e reativas no recôncavo baiano. Tradicionalmente a perfuração tem sido feita com fluidos não aquosos. Por restrições ambientais, devido à presença de aquíferos, houve requerimento que a perfuração da fase 12 1/4" até 1400 m fosse com fluido aquoso isento de cloretos. A Comparação da performance de diferentes fluidos aquosos definiu nano-fluido como possível solução. Em 2017 foi feita 1a aplicação de nano-fluido na fase de 12 1/4" no poço 1-UR-2-BA, na qual foi verificado excelente performance, registrando-se ótimos resultados quanto a torque, pressão e ROP quando comparada à perfuração com fluido sintético. Devido a elevado tempo de exposição rocha-fluido, por conta de problemas operacionais, foram observados cascalhos anormais, indicando instabilidade do poço. Estudo geomecânico incluindo análise de interação rocha-fluido, tempo de exposição e invasão de fluido foi desenvolvido no sentido otimizar as propriedades do fluido quanto à capacidade de inibição e invasão. A 2a aplicação de nano-fluido com as propriedades de inibição e selamento otimizadas foi realizada em 2019, perfurando fase de 12 1/4" do poço 1-GREN-1D-BA até 1386 metros, incluindo a perfuração de 600 metros da formação Pojuca. Visando à otimização da performance, fez-se utilização de motor de fundo para aumentar ROP, reduzindo o tempo de exposição da formação. A descida do revestimento de 9 5/8" até profundidade final caracteriza-se como indicador da efetividade das soluções de otimização de performance implementadas.

Palavras-chave: Fluido de Perfuração. Motor de Fundo. Instabilidade. Formação Pojuca. Otimização. 


\section{Composição da Obra}

Dimensões: A4

Característica: Digital

Formato: PDF

Números de páginas: $50 \mathrm{f}$.

Paleta de cores: Capa (color); Miolo (p\&b)

Estilo da fonte: Calibri Light 
As novas oportunidades, são oriundas do Programa de Revitalização da Atividade de Exploração e Produção de Petróleo e Gás Natural em Terra (REATE), anunciado pelo Ministério de Minas e Energia em 27 de Janeiro de 2017, com objetivo de revitalizar as atividades de E\&P em áreas terrestres no território nacional, estimulando assim o desenvolvimento local e regional aumentando a competitividade da indústria petrolífera onshore.

O desinvestimento dado pela Petrobras nos últimos anos, vem ocasionado queda na produção dos campos terrestres e por consequência a redução na arrecadação de Hoyalties aos municípios produtores. A chegada de novas empresas, petrolíferas, no Rio Grande do Norte é vista com otimismo pelos segmentos envolvidos dado a possibilidade de reativação de setores que tiveram suas atividades paralisadas.

A Universidade Federal Rural do Semi-Árido, em parceria com a Redepetro e o Sebrae tem o prazer em apresentar o I SIMPÓSIO DE PETRÓLEO E GÁS DO ONSHORE BRASILEIRO, cujo objetivo é reunir profissionais, estudantes e pesquisadores da área de petróleo e gás com ênfase na exploração onshore trazendo um ambiente de desafios, oportunidades e aproximando a universidade do setor produtivo.
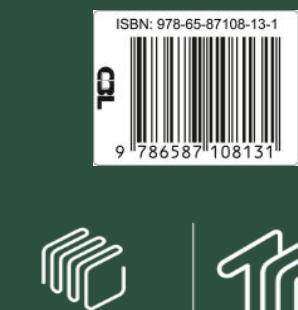